\title{
IMITATION FORECAST OF RAILWAY SYSTEM OPERATION IN A MACROREGION
}

\author{
V.V. DOBRODEY ${ }^{1}$, L.D. GITELMAN ${ }^{1}$, M.V. KOZHEVNIKOV ${ }^{1} \&$ N.A. MATUSHKINA ${ }^{2}$ \\ ${ }^{1}$ Ural Federal University, Russia. \\ ${ }^{2}$ Institute of Economics, The Ural Branch of Russian Academy of Sciences, Russia.
}

\begin{abstract}
The article describes an analytical and information system that was used for forecasting the operation parameters of the railway system in a macroregion of Russia - the Far North. Its economy is focused on the extraction and processing of hydrocarbons, metal production, construction materials, and generate large volumes of exports and inter-regional cargo flows. The region covers an expansive territory and is characterized by harsh weather, an extreme environment, and uneven development of the transportation network. Research into the transportation issues of economic development in such areas presents a challenging task because the region is unique, statistical data are incomplete and classified; there is a hierarchy of businesses and organizations operating in the region that have their own goals and objectives and compete against its other; the region is plagued with social and environmental problems and a lack of administrative integration between individual districts. Using rigorous mathematical tools for assessing transportation infrastructure projects under such conditions is only limited to finding solutions to stand-alone problems and scenario comparison.

A model of the applied system that is outlined in the article makes it possible to analyze specific projects of regional railway system development that take into account strategic priorities and goals of the state, social and economic development problems experienced by the neighboring regions, the oil and gas sector and major employers, as well as corporate goals of the sustainable development of railway companies. The application of the model over an extended period of time showed that the analysis of the structure of cargo flows and customers bound to junctions of the transportation network makes it possible to suggest what aspects of the railway infrastructure should be reorganized in line with the development dynamics of economic entities that consume transportation services. The study is built upon a number of projects that were implemented in the north of Tyumen Region and the YamalNenets and Khanty-Mansi autonomous areas of Russia.
\end{abstract}

Keywords: aggregated cargo flows, balance, cargo correspondence, dynamics, efficiency, forecast, model, region, resilience, territorial complex, uncertainty.

\section{INTRODUCTION}

It's a known fact that transportation systems, along with the power supply and communications networks, are an example of so-called critical infrastructure. From the strategic point of view, the railway system is the most important of all modes of transportation: on the one hand, railways make it possible to deliver significant numbers of passengers and large amounts of cargo to remote areas relatively quickly. On the other hand, being a complex system, rail transport is the slowest to recover after unforeseen perturbations (such as a terrorist attack, a natural disaster, or a transport accident). This might be the reason why a number of foreign studies dedicated to the sustainable development of rail infrastructure exhibit the influence of the theories of anti-crisis management non-linear systems $[1,2]$.

Major production companies are the most active consumers of rail cargo services. They often act as co-investors in new railway construction projects that are aimed at the development of hard-to-access areas. Such projects are capital-intensive and have long pay-back 
periods [3]. This is why planning the expansion of rail infrastructure is based on forecasts of territorial development and demand for railway services in order to ensure the maximum capacity utilization rate $[4,5]$.

Transport system operation in remote areas is a valid research subject in many countries. Projects of major significance to the Russian economy have to do with the development of rail infrastructure in northern regions due to the pressing need to effectively explore and extract fossil fuels and minerals there, especially oil and gas fields that are the major source of revenue (over 40 per cent) for the country and account for 50 per cent of national exports. The biggest share of the resources is located in the east and north of the country. Transportation costs (including all related expenditures) make up a considerable part of production and delivery costs, becoming a decisive factor in the practicability of creating specific facilities and infrastructure. Additionally, proper transportation arrangements in northern regions are thwarted by adverse weather conditions. It is, therefore, necessary to make sure that the following issues are taken into account when analysing the above issues:

- Factors of transport system development at the level of the region and the country as a whole.

- Prospects for the development of interregional ties and regional economies.

- Analysis of the overall state of the region's transport infrastructure and its key operational results, and existing governance mechanisms.

- The findings of a feasibility study into the prospects of developing specific means of transport and evaluation of priorities for the regional transportation policy.

Another big area for improvement of the transport system operation has to do with the need to expand and ensure the sustainable operation of rail infrastructure that plays the most important role in solving the transportation problems of Russia's northern regions. The list of priorities here includes the reorganization of main production and auxiliary units, adoption of new technological solutions, renewal of rolling stock, development of repair facilities and their dedicated services and technical and maintenance support. Institutional and organizational differences, a lack of departmental and territorial integration between companies and organizations involved in transportation activities and, as a result, a narrower choice of effective freight shipping schemes negatively affect the effectiveness of the local economy. There is no doubt that rational proportions of various modes of transport and interrelated dynamics of their development and use should be found [6], the interests of the main key cargo generating companies and owners of rolling stock should be taken into account in order to optimize the utilization of railway capacity $[7,8]$.

\section{RESEARCH METHODOLOGY}

To study development issues of a regional railway system, an analytical information system was designed that makes it possible to structure the processes of analysing general problems of boosting the effectiveness and sustainability of the railway system as well as individual railway infrastructure development projects [9]. The authors believe that the approach provides for a fuller appreciation of the impact that the implementation of local projects and programmes has on integral indicators of the system performance. The logical structure of the imitation system that was used by the authors for calculations includes information and 
forecasting modules (Fig. 1) and an associated assortment of targeted blocks that can be picked out to fit specific investigations. For example, the following blocks were used for calculations:

- Development, deployment and introduction of dedicated services of rolling stock repair facilities, including maintenance support;

- Development of the railway network in emerging regions;

- Restructuring of management and development of auxiliary and support facilities;

- Forecasting of the structure of the customer base and demand for shipping services etc.

The method of building and comparing scenarios that was used for the research implies that a variety of instruments are used for quantifying target indicators. The instruments are econometric and balance models, expert analysis, professional-grade software solutions for analysis of investment projects, special procedures for adjusting results with projections and programmes of social and economic development, etc. The structure of the system is aimed at ensuring the variability of conclusions and incorporates non-formalized stages and procedures of logical, economic and system analysis. Additional information modules were created for specific projects to cater for the features of the problems under study.

A brief description of corresponding blocks of the suggested model as applied to the conditions of the Urals Federal District (UFD) can be summarized as follows.

Assessment of the place and role of the transport system of the UFD in the unified transport system of Russia (block 1 of the model) leads to the following conclusions. Geopolitical and geo-economic location of the UFD and its infrastructure directly influences the factors of functioning and development of transport:

- Configuration of railway and road networks.

- Directions and volumes of main cargo flows.

- Ratio of transit and local operations.

- Structure of carried cargo, etc.

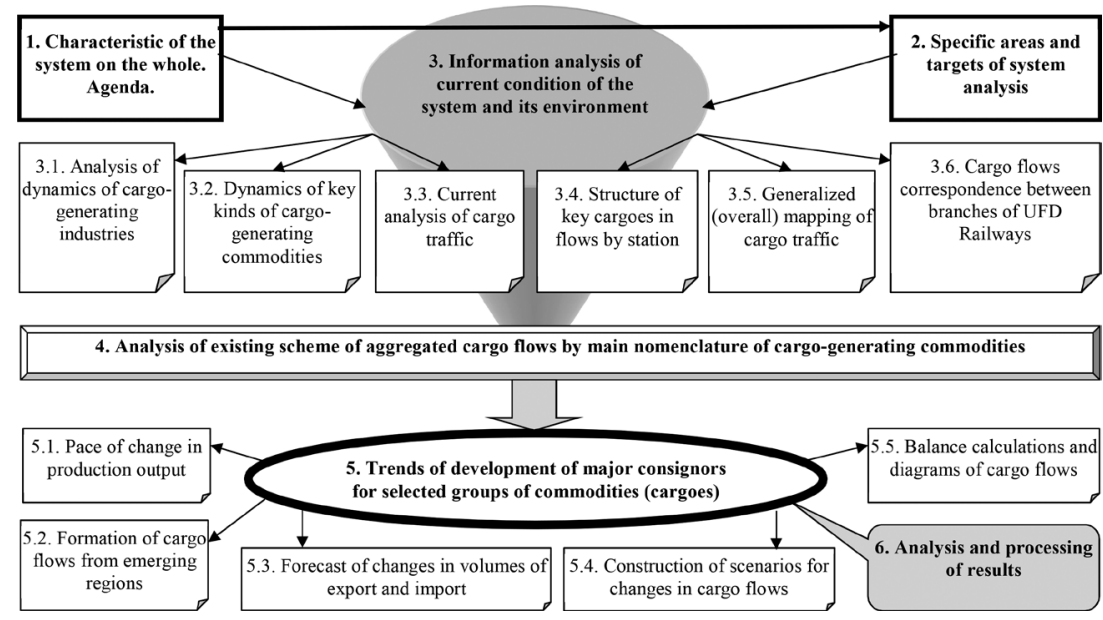

Figure 1: Information and forecasting modules of imitation system of transportation system operation in a region. 
The following is a list of advantages that determine the role and prospects of the transport sector of the Urals Federal District:

- The economic potential and geographical position in the middle of Eurasia at the border between European and Asian subcontinents.

- Almost one third of all proven fossil fuel reserves, one sixth of iron ores, $4.5 \%$ nonferrous metal ores, almost $10 \%$ of wood.

- A massive industrial complex.

The economic position of transport is defined by a set of factors:

- Importance and prospects (tendencies) of development of the economy of the area where services are provided (i.e. the size and structure of transportation services market).

- Position and role of the UFD in the national economic space and the world economy, the position and role in the integrated network of transport communications, geographical and mode structure of traffic.

- Common trends in the government's industrial, regional and technological policies.

- Global economic tendencies: interworking of interests on global markets and subsequent processes (integration and competition of economies, globalization of the world economy).

The importance of this set of factors stems from the current issues of integrating the Urals macroregion into the global transport network [10].

The purpose of specific investigations in the given segment of the model (block 2) is to provide economic justification of mid-term prospects for changes in main cargo flows that define the sustainable development of regional transport systems as an important constituent of the regional economy while taking into account their role in forming the integrated economic space of Russia, processes of integration of the country into the world economic system.

The primary focus here is on forecasting possible changes in cargo flows serviced by railroads, considering the basic nomenclature of carried cargoes. The main factors of upcoming changes are seen as immediately proceeding from development trends in major industrial complexes and the largest cargo-generating businesses in the Urals, West Siberia as well as from the prospects of allocation of productive powers, economic development of emerging, and primarily, northern areas, international business activity. The research yields the following data and their substantiation:

- Basic and forecast station-by-station balances on arrival and dispatch of cargoes in view of their main nomenclature.

- Forecast interactive schemes of aggregated cargo flows with reference to territory.

- Summary data on cargo flows in territorial branches of the railroad and the largest industrial and transportation junctions.

- Forecast schemes of cargo correspondence between branches.

Due to the complexity of the system and its interconnections a range of relatively independent stages in the implementation of block 3 was set out. The analysis of dynamics of 
cargo-generating industries made it possible to collect vast analytical material including, together with retrospective industrial indexes, the characteristics of cargo flows:

1. Current condition of cargo flows classified in line with the nomenclature, its structure by arrival and dispatch; import and export of industrial and technical cargoes.

2. The nomenclature of the most important cargo-generating commodities, their share in arrival and dispatch station-to-station.

3. Generalized (summary) display of aggregated cargo flows by stations and branches.

4. Balance calculation and active diagrams of cargo flows for the reference period of time.

Calculations were automated in order to simulate forecast indices (block 4). The structure of cargo flows was defined for all kinds of aggregated goods - thermal and coking coal (in the context of major enterprises), iron ore, cast iron, steel, rolled metal, pipes, cement, construction cargoes, non-ferrous ores (aluminum and copper industry), titanium-magnesium, chromite and other ores, petroleum cargoes, potassium fertilizers, timber cargoes, other cargoes for railways. Moreover, receiving stations arrival and main corporate customers were determined and assessment was performed for evolving dynamics of coal cargo flows.

The architecture of block 5 of the model reflecting stages of formation of forecast cargo flows is given in a simplified form. All elements of this block are interconnected and it appears practical to highlight relatively independent blocks of the forecast, with interconnections between being irregular. Analytical results for each block are incorporated into a total result - scenarios of prospective changes in cargo flows - on the basis of logic and economic analysis and formal calculation procedures. Some of the blocks, namely, block 5.2 of the model (assessment of opportunities for formation of prospect cargo flows from emerging regions), are characterized by high uncertainty of future factors, since investment in new production facilities might generate new cargo flows. This enhances the qualitative characteristics of the forecast and proves it wrong to attempt to bring it down to formalized calculations only.

Annual parameters of cargo flows over past periods were determined on the basis of corporate statistics that was made available to the authors for the purpose of conducting the feasibility studies of targeted development projects. In order to reduce the amount of analysis to be done, the obtained indicators describing individual railway stations and sections of the network within a specific module of factors, were, if necessary, supplemented with such indicates as 'the number of wagons', 'type of wagon', cargo turnover etc. The modules of the system also contained different ranges of aggregated cargo. Despite a significant volume of calculations, individual calculation modules rest upon simple logic and are easy to automate, which makes the creation of cargo flow scenarios less labor-intensive. The formalized correlations that were used are typical of transportation and logistics problems [11-15]; their simplified descriptions are given below.

$i=1 . . . k$ - aggregated nomenclature of cargoes; $j=1 . . n$ - stations;

$O t p^{j}$ - volume of cargo dispatched from a station $\boldsymbol{j}$ (in all directions);

$\operatorname{Pr}^{j}-$ volume of cargo arriving at a station $\boldsymbol{j}$ (from all directions);

cargo flows between two adjacent stations: $V^{j, j+1}-$ volume of cargo traffic between stations $j$ and $j+1$;

$$
, V^{j, j+1}=\sum_{i=1}^{k} \vec{V}_{i}^{j, j+1}+\sum_{i=1}^{k} \bar{V}_{i}^{j, j+1}
$$


where $\vec{V}^{j, j+1}, \bar{V}^{j, j+1}$ - volume of cargo traffic $i$ between stations $\boldsymbol{j}$ and $j+1$ in outbound and return journeys correspondingly (volume of cargo dispatch is equal to volume arriving at the address station). For cargo flows scenarios, limits on carrying capacity of single-track and double-track lines were taken into account as well as the throughput of stations: $S_{j}=\sum_{i=1}^{k} S_{i}^{j} \leq F^{j}$, where $F^{j}$ - carrying capacity of station $j, S^{j}-$ volume of cargo coming through station $j$, equal to the sum of arrivals from all directions and loading of certain aggregated cargoes: $S_{i}^{j}=\operatorname{Pr}_{i}^{j}+P g r_{i}^{j}$. Thus, the balance of cargo flows at the station is described by the ratio:

arrival and loading: $\operatorname{Pr}^{j}=\sum_{i=1}^{k} \operatorname{Pr}_{i}^{j}, P g r^{j}=\sum_{i}^{k} \operatorname{Pgr}_{i}^{j}$;

dispatch and unloading: $O t p^{j}=\sum_{i=1}^{k} O t p_{i}^{j}, V i g^{j}=P r^{j}+P g r^{j}-O t p^{j}$.

Given the already known factors of import $V v^{j}$ to and export $V z^{j}$ from other railroads for every station $j$, a balance for every kind of cargo and the whole complex will be determined as:

$$
\begin{aligned}
& O t p_{i}^{j}+V v_{i}^{j}=\operatorname{Pr}_{i}^{j}+V z_{i}^{j} \\
& \sum^{k} O t p_{i}^{j}+\sum^{k} V v_{i}^{j}=\sum^{k} P r_{i}^{j}+\sum^{k} V z_{i}^{j}
\end{aligned}
$$

Similarly, the balance of cargo flows by branch (region of operation) of the railroad and by each kind of cargo and all cargoes is determined ( $\boldsymbol{m l}$ - number of stations in a branch) as:

$$
\begin{gathered}
\sum_{j=1}^{m l} O t p_{i}^{j}+\sum_{j=1}^{m l} V v_{i}^{j}=\sum_{j=1}^{m l} P r_{i}^{j}+\sum_{j=1}^{m l} V z_{i}^{j} \\
\sum_{j=1}^{m l} \sum_{i=1}^{k} O t p_{i}^{j}+\sum_{j=1}^{m l} \sum_{i=1}^{k} V v_{i}^{j}=\sum_{j=1}^{m l} \sum_{i=1}^{k} P r_{i}^{j}+\sum_{j=1}^{m l} \sum_{i=1}^{k} V z_{i}^{j}
\end{gathered}
$$

Correspondence with other branches is specified in cargo flows. The cargo flows for the railway system as a whole is structured in the same way - import and export of every kind of cargo, all cargoes, and its components - by specific stations, considering correspondence with other railways. For example, the cargo flow by cargo types and the total cargo flow are described by ratios (4) and (5), replacing the number of stations $m l$ with $n$.

Scenarios of changes in cargo traffic are built in block 5.4 of the model. The entire process was divided into several stages (steps). That made it possible to look at individual scenarios that are related to general development conditions for the territories' economies and their interconnections with other regions, as well as scenarios that reflect changes in production and technological links between industries and major cargo-generating companies. In accord- 
ance with the research goals, the analysis was limited to identifying key trends in cargo traffic and assessing the general rate of change under the selected scenarios.

The problems that were taken into account are of strategic development of transport infrastructure that are addressed at the federal level, which is most vividly expressed in a targeted project for the completion of railways in the northern areas of the Urals, as well as regional problems. The most complicated methodological task is to forecast freight demand due a large number and variety of cargo-generating companies. Statistical and analytical models were used for the task in combination with data from accepted forecasts of the socio-economic development of areas in the catchment area of the railway network being considered. When building the scenarios on the basis of retrospective information, base case (inertial) scenarios trends in cargo traffic were identified that were adjusted for future periods, taking into account big investment projects and local socio-economic development programs. Information that was used in calculations encompassed major customers of junction stations, interaction with other means of transport, demand for passenger transportation and changes in transit cargo traffic.

The authors believe that such structuring of procedures for analysis of retrospective data and of scenario building stages allows for taking fuller account of the interests of those who purchase shipping services, and to identify directions for the sustainable development of the territorial railway system. From a formal point of view, the described analytical system is a reflection of a distributed imitation research process. For applied calculations the system was supplemented with procedures that improved its functional value. To achieve that, each block of the system was divided into smaller ones for the sake of functional decomposition and a greater detail of analysis, in order to add more methods and computations, extra output data, and information links with other blocks. The use of active graphic visualisation of information flows in the system makes it possible to consistently rationalise its structure and the logic of links between various stages of the study and, eventually, to ensure the system's adequacy to existing and projected parametres of collaboration between the transportation system and businesses in the region.

\section{APPLICATION}

The imitation analytical system proved highly effective in building development scenarios for the railway system of a macroregion. Information base monitoring enabled the authors to use it when:

1. Interrelated investment projects for the development of rail transport.

2. Variants of reforming, restructuring and technical development of the subsystems of company-owned rail stock and facilities, and of the strategy and tactic of raising their competitive advantage in view of competition between modes of transport.

3. Introduction of modern organization and economic technologies of effective management that include the creation of effective marketing mechanisms for transport.

4. Development, deployment and introduction of dedicated services of rolling stock repair facilities, including maintenance support.

The results of project research made it possible to expand and bring the information database of the imitation system up to date and to monitor the development indicators of the transportation system of the region. 
In illustrating the effective application of the imitation system we shall limit ourselves to brief descriptions of two projects that were actually implemented - a project for the development of the railway network of the Yamal-Nenets Autonomous Area and a project for the development, deployment and introduction of dedicated services of rolling stock repair facilities (including maintenance support) of Sverdlovsk Railways.

The first project essentially seeks to conquer promising transport services markets to speed up the development of oil and gas deposits in the north and to further the economic development of the region in line with the project analysis methodology adopted for the Urals macroregion $[16,17]$ :

1. To establish favourable conditions for speeding up the development of northern deposits by means of improving transportation infrastructure as well as by reducing the share of shipping costs in the overall cost of resources being consumed by the region.

2. Development of meridian routes to access the Northern Sea Route развитие меридиональных выходов к Северному морскому пути [18, 19].

3. To develop passenger transport to fully meet the needs of the region's population.

4. To improve the operational effectiveness of regional railway segments.

The project had the following objectives:

- To complete the Korotchayev - Novyy Urengoy - Pangody - Nadym - Pristan rail line and the Novyy Urengoy - Yamburg link, the costs being shared by Russian Railways, Gazprom, the government of the Yamal-Nenets Autonomous Area and other interested parties (Fig. 2).

- To put into service a rail link and arrange passenger traffic to Novyy Urengoy.

- To draft, in cooperation with the government of the Yamal-Nenets Autonomous Area, a general development strategy for the region's transport infrastructure.

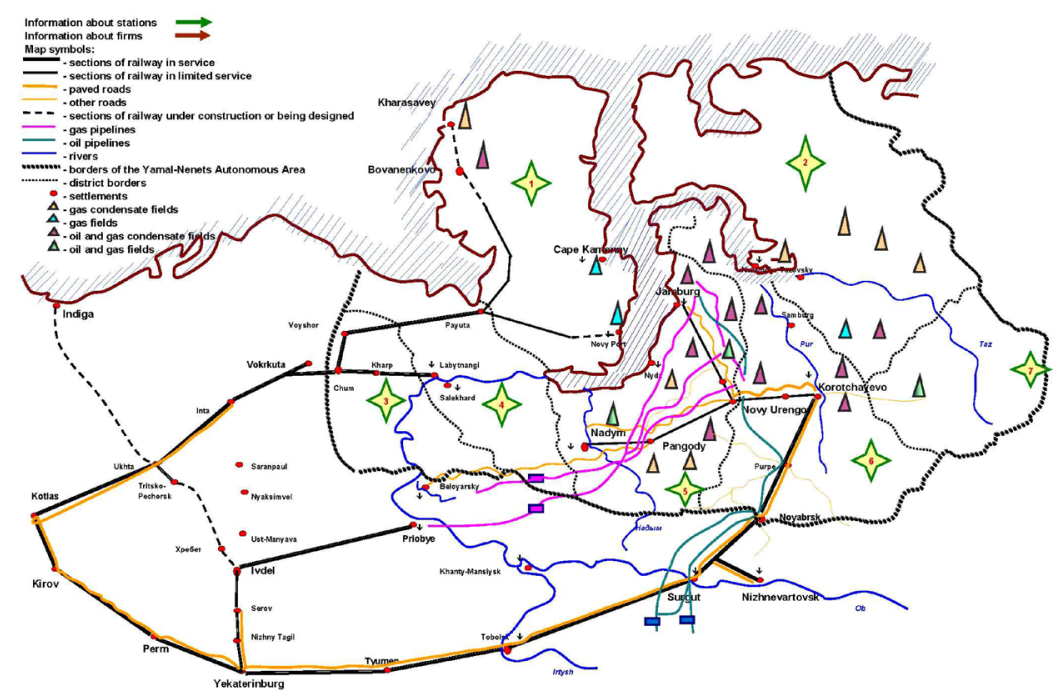

Figure 2: Index map for assessing the problems of completing sections of railway in the Yamal-Nenets Autonomous Area. 
The feasibility study for the project included analysis of the prospects of development of oil, gas and gas condensate fields in the catchment area of the rail links being built, a social and economic profile of the Yamal-Nenets Autonomous Area, its mineral reserves, the dynamics of the oil and gas industry. It considered options for shipping hydrocarbons by various means of transport and the resulting combinations of aggregate cargo flows. Scenario hypotheses took into account output forecasts for natural gas, gas condensate, crude oil, deliveries of construction supplies and other staples, detailed dynamics of production indicators and demand for shipping services by major customer of key stations of the railway network. Expected financial and socio-economic results of the project were also evaluated.

The expansive construction of the Tobolsk-Surgut-Korotchayevo railway link continues as part of the project; the volume of fuel cargo shipments that the link handles has been growing and is to reach $40 \mathrm{~m}$ tonnes a year in 2016.

The main goals of the second project was to address the issues of sustainable development and reorganization of the rolling stock repair facilities and auxiliary services of Sverdlovsk Railways, a territorial transportation complex. One of the main tasks was to increase revenue from its wagon fleet by improving its organizational structure and its key production unit - the traction and rolling stock maintenance depot. The lack of advance information about the possible workload of maintenance depots that will come from key customers in a medium term perspective makes it difficult to take effective management decisions and leads to unreasonable losses for the railway as well as for the region's manufacturing companies that have a large and mixed wagon fleet of their own.

A prognosis of the structure and volume of the wagon flee provides a basis for evaluating the prospects of development and specialisation of repair and maintenance services. The scenarios build upon information about the owners of the largest wagon fleets and operate in the area serviced by Sverdlovsk Railways.

Among the factors taken into account were the structure and composition of the wagon fleet in terms of its deployment and wagon types, its clustering and the ensuing differences in demand for and profitability of day-to-day maintenance and major repairs to extend the service life of rolling stock (SLE). The forecast of maintenance needs of the owners of wagons and Russian Railways is based upon the estimated future shipping needs to be met by Sverdlovsk Railways and a prognosis of potential changes in the composition of the wagon fleet. To provide a more accurate estimate and identify the prospects of the fleet development and future demand for maintenance services, the heads of transport departments of over 50 companies each owning more than 100 wagons were surveyed. The purpose of the survey was to:

- Collect data about the number and types of wagons owned by the companies, including decommissioned and newly purchased ones.

- Assess the impact (elasticity) of lower prices of wagons and maintenance fees charged by depots on the number of newly acquired wagons.

- Identify the depot services that are of the highest value to companies owning a fleet of wagons.

- Identify the customers' preferences for specific depots.

- Examine the routes that are most commonly serviced by privately owned wagons.

Two scenarios that are used in the formal calculations - a 'baseline' one and a 'territory-specific' one - differ in parametres that characterize the structure of the wagon fleet, the decommissioning and procurement of wagons, development and specialisation options of depots etc. The 
second scenario is largely a vision of Sverdlovsk Railways experts of what depots should specialise in, how they should be assigned to specific wagon fleets and utilize their capacity.

We proceed from a hypothesis that the original (basic) structure of inventory and operational wagon fleets (in terms of wagon types) is pretty much reflective of the territory-specific structure of shipping needs in the Sverdlovsk Railways service area. Future changes in the structure of the wagon fleet are determined by:

- The regional dynamics of freight shipping needs, e.g. a growth in coal cargo, metals, construction materials etc.

- Uneven distribution of new-generation wagons being added to the car fleet.

- Territory-specific redistribution of freight by types of rolling stock.

In the general calculation scheme (Fig. 3), statistical data processing played a supplementary role.

The performed module of calculations offers a set of automated procedures that make it possible to significantly reduce the labour intensity of obtaining quantitate evaluations of

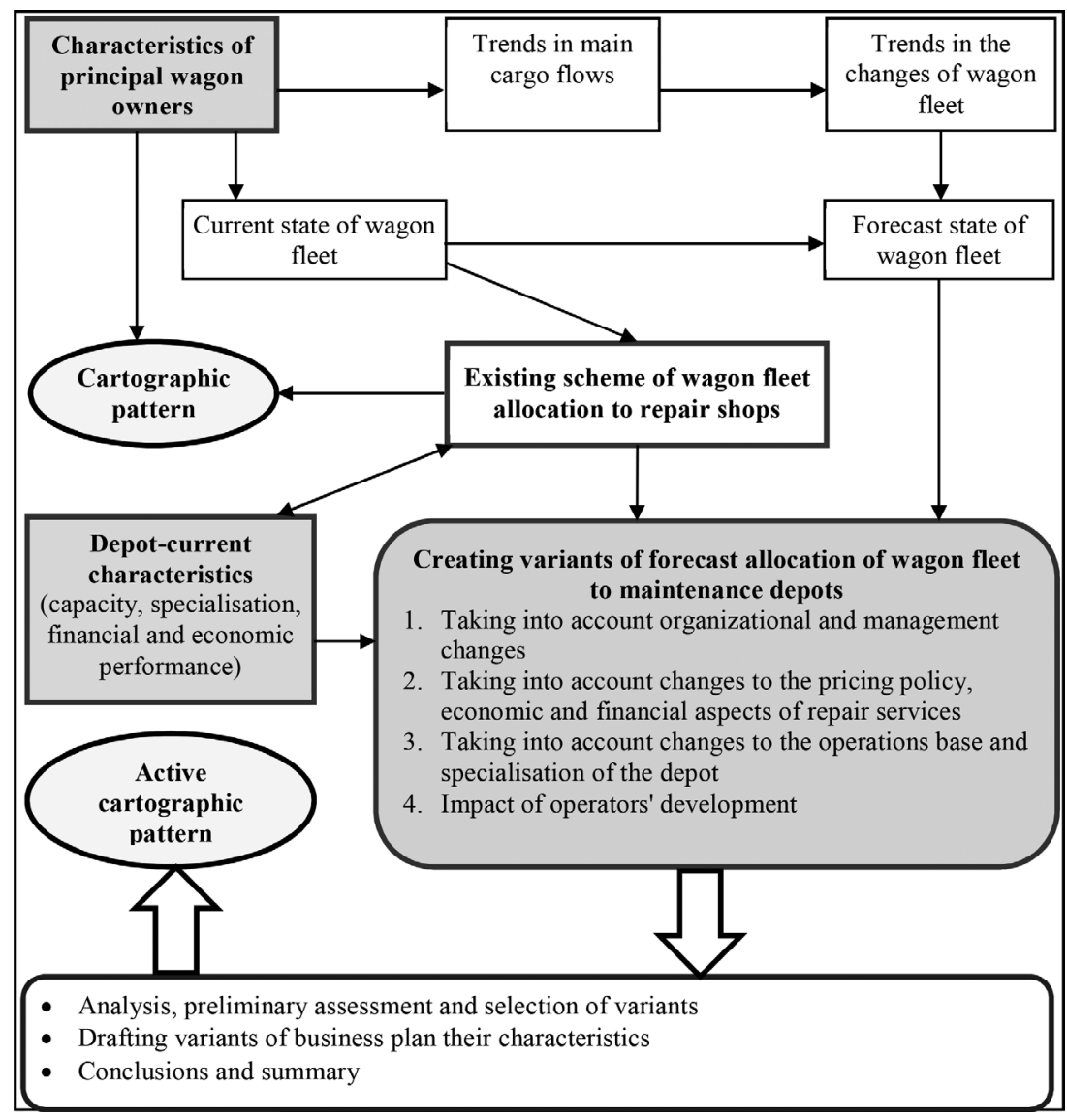

Figure 3: General algorithm of the assessment of possible allocation of wagon fleet to maintenance depots. 
the variants and ensures integer balance of the dynamics of the inventory fleet and repair capacity utilization. The created information blocks that reflect the characteristics of wagon owners, performance indicators, specialisation and capacity of depots can be updated automatically and are linked to active charts. Changes in the information are automatically incorporated into variant calculation procedures. There is also a separate block of calculations to assess the risk of business plan variant (not shown in Figure 3).

The study of the rolling stock repair facilities of the railway branch showed that the majority of problems associated with their reform and development goals are poorly structured and are not subject to formalization. Consequently, the option assessment criteria included metrics that did not allow for precise quantification. Moreover, the dynamic assessment of environmental, social and political aspects can hardly be done in monetary terms, while the application of expert procedures for forecasting potential major changes in the external environment (including technology, law etc.) boils down to random choice amid seriously incomplete information.

\section{CONCLUSIONS}

The creation of the applied imitation and analytical system revealed a number of scientific, methodological and information problems that make it more difficult to apply it in specific projects. The prime one is the uncertainty in economic results of reforming the organizational structure of transport system subdivisions, current and future assessments of environmental factors and their significance. As a result, there is substantial instability (variability) of the customer base structure and the composition and volume of cargo flows that strongly affects the indicators of transport effectiveness and the resilience of the railway system. That's why it becomes quite a challenge to select the most significant factors and hypotheses when building scenarios in specific projects. The use of the applied analytical system under such conditions makes it possible to increase the variability and volume of analytical data, to estimate expected results within various hypotheses for the development of the economy and demand for shipping services and, to a certain extent, to assess the probability of the results in the mid term future.

The research conducted by the authors shows that the application of the "completeness of factors' principle when analyzing the issues of transport system development in a region, as well as their multitude, interdependence, possible contradiction, hierarchical structure and relative uncertainty underscore the advantages of using the integrated approach to that was employed by the authors in their system of assessing the directions of sustainable development and operation of regional transport infrastructure. The system combines formal statistical and balancing methods and the instruments of economic logic, expert assessment and scenario constructions. It also makes it possible to offset, to a certain degree, the incompleteness and inaccuracy of information being used.

The application of the author's system for forecast calculations in a number of projects aimed at the restructuring and development of the regional railway system and solving regional transportation problems prove that the methods and analysis schemes are quite precise [20]. More specifically, the novelty of the approach is a method of immediate recognition of the specific features of the territory from the point of view of deposit exploration dynamics, its economic potential, geographic characteristics, it's role in the national economy, and the quantitative assessment of future shipping needs on the basis of recurrent balance calculations. 


\section{ACKNOWLEDGEMENT}

The work was supported by Act 211 Government of the Russian Federation, contract № 02.A03.21.0006.

\section{REFERENCES}

[1] Adjetey-Bahun, K., Birregah, B., Châtelet, E. \& Planchet, J.-L., A model to quantify the resilience of mass railway transportation systems. Reliability Engineering and System Safety, 153, 2016, pp. 1-14.

http://dx.doi.org/10.1016/j.ress.2016.03.015

[2] Gao, Y., Yang, L. \& Li, S., Uncertain models on railway transportation planning problem. Applied Mathematical Modelling, 40, pp. 4921-4934, 2016.

http://dx.doi.org/10.1016/j.apm.2015.12.016

[3] Gattuso, D. \& Restuccia, A., A tool for railway transport cost evaluation. Procedia Social and Behavioral Sciences, 111, pp. 549-558, 2014.

http://dx.doi.org/10.1016/j.sbspro.2014.01.088

[4] Rao, P.S., Forecasting the demand for railway freight services. Journal of Transport Economics and Policy, pp. 7-26, 1978.

[5] Liden, T., Railway infrastructure maintenance - a survey of planning problems and conducted research. Transportation Research Procedia, 10, pp. 574-583, 2015. http://dx.doi.org/10.1016/j.trpro.2015.09.011

[6] Tatarkin, A.I., Gimadi, I.E., Dobrodey, V.V., Matushkina, N.A., et al., Transport Strategy of the Urals Federal District, [in Russian], Economika: Moscow, 2004.

[7] Kuo, A. \& Miller-Hooks, E., Combinatorial auctions of railway track capacity in vertically separated freight transport markets. Journal of Rail Transport Planning \& Management, 5, 2011, pp. 1-11.

http://dx.doi.org/10.1016/j.jrtpm.2014.12.001

[8] Rodrigue, J.-P., Transport geography should follow the freight. Journal of Transport Geography, 14, 2006, pp. 386-388.

http://dx.doi.org/10.1016/j.jtrangeo.2006.06.003

[9] Dobrodey, V.V., Gitelman, L.D., Kozhevnikov, M.V. \& Matushkina, N.A., Information and simulation model for complex regional transport. WIT Transactions on the Built Environment, 146, pp. 485-493, 2015.

http://dx.doi.org/10.2495/UT150391

[10] Litovskij, I.A., Litovskij, V.V. \& Petrov, M.B., Railway transport communications and spatial paradigm of development of the Urals. Spatial paradigm of poorly studied areas development. Experience, problems and solutions, [in Russian], Ural Branch of the Russian Academy of Science: Ekaterinburg, pp. 88-108, 2009.

[11] Zhang, Q., Jiang, C., Zhang, J. \& Wei, Y., Application of genetic algorithm in functional area layout of railway logistics park. Procedia - Social and Behavioral Sciences, 138, pp. 269-278, 2014.

http://dx.doi.org/10.1016/j.sbspro.2014.07.204

[12] Rodrigue, J.-P., Comtois, C. \& Slack, B., The Geography of Transport Systems, Routledge: London and New York, pp. 38-72, 2006.

[13] Burdett, R.L., Optimisation models for expanding a railway's theoretical capacity. European Journal of Operational Research, 251, pp. 783-797, 2016. http://dx.doi.org/10.1016/j.ejor.2015.12.033 
[14] Vansteenwegen, P., Dewilde, T., Burggraeve, S. \& Cattrysse, D., An iterative approach for reducing the impact of infrastructure maintenance on the performance of railway systems. European Journal of Operational Research, 252, pp. 39-53, 2016. http://dx.doi.org/10.1016/j.ejor.2015.12.037

[15] Barelkowski, R., Planning for sustainable development of energy infrastructure: fast - fast simulation tool. International Journal of Energy Production and Management, 1(1), pp. 61-71, 2016. http://dx.doi.org/10.2495/EQ-V1-N1-61-71

[16] Conceptual framework for building and implementing the project "Industrial Urals Polar Urals, [in Russian], eds. A.I. Tatarkin, Economy: Moscow, 2007.

[17] Matushkina, N.A., Averina, L.M. \& Dobrodey, V.V., From Lomonosov's ideas to real exploration of Urals, Siberia and Far East, [in Russian]. Institute of Economics of the Urals Branch of the Russian Academy of Sciences: Ekaterinburg, 2009.

[18] Suhih, V.V., The fuel factor in the development of the Northern Sea Route in the early XX century. Oil and gas in Western Siberia: Materials of the international scientific and technical conference. Vol. 6. The social and humanitarian aspects of the modernization of Russia, [in Russian], Tyumen State Oil and Gas University: Tyumen, pp. 211-216, 2015.

[19] Suhih, V.V. \& Vazhenin, S.G., Public-private development projects in the Polar Urals. Transport Corridor "Ural Industrial - Ural Polar". Results and prospects, [in Russian], Institute of Economics of the Urals Branch of the Russian Academy of Sciences: Ekaterinburg, pp. 178-195, 2010.

[20] The new business model of transformation of Russian Railways into an international transportation and logistics holding company is in the process of implementing, [in Russian], available at: http://www.rzd-partner.ru/news/transportnaia-logistika/novaiabiznes-model-preobrazovaniia-rzhd-v-mezhdunarodnyi-transportno-logisticheskiikholding-nakho/ 